\title{
A SOLUTION-BASED POSITION PAPER OF THE NIGERIAN YOUNG ACADEMY ON SEX-FOR-GRADES MENACE ACROSS NIGERIAN TERTIARY INSTITUTIONS
}

\author{
Mohammed Auwal Ibrahim 1,5*, Temitope O. Sogbanmu ${ }^{2,5}$, Oluwasola E. Omoju ${ }^{3,5}$, and \\ Kingsley N. Ukwaja ${ }^{4,5}$
}

\author{
${ }^{1}$ Department of Biochemistry, Ahmadu Bello University, Zaria, Nigeria \\ ${ }^{2}$ Department of Zoology, University of Lagos, Nigeria \\ ${ }^{3}$ National Institute for Legislative and Democratic Studies, Abuja, Nigeria \\ ${ }^{4}$ Department of Internal Medicine, Alex Ekwueme Federal University Teaching Hospital Abakaliki, Nigeria \\ ${ }^{5}$ Member, Nigerian Young Academy
}

Received $2^{\text {nd }}$ June, 2020, Accepted $22^{\text {nd }}$ June, 2020

DOI: 10.2478/ast-2020-0008

*Corresponding author

Dr.Mohammed A.Ibrahim E-mail:mauwalibrahim@gmail.comor maibrahim@abu.edu.ng

\section{Introduction}

The Nigerian Young Academy (NYA) was inaugurated by the Nigerian Academy of Science (NAS) at the instance of the Global Young Academy (GYA) based in Berlin, Germany. The Academy is a unified platform for interaction among brilliant young researchers below the age of 45 years in Nigeria from various research disciplines. The NYA promotes the application of collective research findings for the improvement of the Nigerian society and plays a crucial role in building inspirational figures for a new generation of researchers. The NYA has her core values entrenched in integrity and excellence in research, and fostering research collaborations among young researchers nationally and internationally. In line with its mission to use scientific research as a pivot for societal development, the NYA occasionally releases position papers on several issues in the Nigerian society. This current position paper relates to the increasing menace of sex-for-grades in the Nigerian tertiary education system.

The important role of universities and academics in shaping the future of a society cannot be overemphasized. They serve as harbingers and producers of knowledge for the advancement of the society and the development of the human race. However, following the recent spike in the incidence of professional misconducts among university academics, especially with respect to sexual harassments in Nigeria, the reputation of the tertiary academic institutions in the country has been called into question. The NYA, as the mouthpiece of upcoming
Nigerian academicians, believe that this will have a dire consequence on the future of younger academics, in particular, and the educational standards of the country in general. Therefore, we organized an indepth survey, and in consultation with literatures, a deep dive analysis of the unpleasant trend was conducted and we curated and harmonized workable solutions that could go a long way to address the menace and improve our educational standard and national life. Following our survey questionnaire administered via Google forms to academics and students across Universities in Nigeria, a total of 73 university academics and 183 university students who responded, opined that, professional ethics among university academics in Nigeria is very poor. In fact, $45 \%$ of the respondents have experienced inappropriate behaviour, even though over $70 \%$ of academics and $60 \%$ of students stated that it is inappropriate or very inappropriate for academics and their students to have consensual relationship. It is also very common for academics in Nigeria universities to demand for favours from students to influence their results. Indeed, representative data from the literature have indicated a prevalence of sexual harassment of $77 \%$ in two (unnamed) Nigerian Universities, $97 \%$ in tertiary institutions of Edo State, $36.7 \%$ in an institution of Ebonyi State, 8\% in Colleges of North Eastern Nigeria, 7.1\% in tertiary institutions of Maiduguri, Borno State, $44.4 \%$ in some faith-based private universities and $32.2 \%$ of Nigerian female graduates serving in Oyo State. 
This might even be uglier when the number of victims who succumb are considered. However, a summary of the remote causes of these inapproapriate behaviours based on the survey responses and literature review are expedient in order to suggest possible solutions.

1. Lecturer-centred causes of sexual abuse: An inherent failure to control sexual urge under different forms of provocations (lack of selfdiscipline) is the major driver of sexual harassment. Sadly, this deficiency is prevalent among most male lecturers as confirmed by a study on the integrity of the Nigerian University system, where $86 \%$ of the interviewed academic staff had sexually harassed a female student at one point or the other in their lecturing career. Other causes of sexual harassment among lecturers are moral weakness, poor remuneration of academics, unwieldy powers of lecturers over courses and single individual course instruction.

b. Student-centred causes of sexual harassment: A very critical, but under-studied, cause of sexual harassment is the female students serving as "initiators" of the process. It is important to note that some female students in Nigerian tertiary institutions deliberately use sex as a weapon for academic and economic survival. It has been established from a survey of sexual harassment in Nigerian Academia that, in most cases, female students out of desperation do propose sexual intimacy to their lecturers in lieu for academic rewards. In fact, a number of lecturers confirmed that they had been sexually propositioned by female students while some female students agreed that it is normal to date a lecturer if the girl wants to have "fun" and the faculty staff can provide it for her. Moreover, some of the female students deliberately engage in sexual relationship with lecturers to acquire the status of a "super girl" on campus where they derive great pleasure and are highly thrilled. Conversely, some students, directly or indirectly, initiate romantic and sexual intimacies with lectures because they are lazy and academically very weak with the hope to exploit the sexual relationship to acquire undeserved grades as a cover for the academic weakness. Other student-centred causes of sexual harassment proposed by female students are indecent dressing, familiarization with lecturers and drug abuse.

c. Institutional causes: It was observed that a number of the Nigerian tertiary institutions have sexual harassment policies but these are largely paper based documents domiciled in a file at the sexual abuse office or any other office in the administration unit of the institutions. Our survey revealed that sexual harassment is compounded by the lack of a proper laid down procedures for complaints and addressing those complaints. From our survey, over $50 \%$ of students and $45 \%$ of academics in various Nigerian universities believe that their institutions do not have a good and transparent laid down procedures for reporting sexual harrassment. There is also a nonchalant attitude from most university managements and are not doing enough to enforce professional ethics among academics. In fact, studies across the country have clearly suggested this, as a reason for failure of the victims to officially report the cases of sexual abuse making the culprits getting away with it. Also, poor vetting of academics by the University management at the point of employment is a major concern.

d. Societal causes: The wrong societal perception that university lecturers are very free is a major factor that makes the profession quite appealing to some individuals. Consequently, people who are morally and ethically unfit for the profession are appointed/employed and end up promoting the sex-for-grades menace. Also, the society places a "high premium" on the higher qualifications which makes students have the quest to acquire the qualifications at all cost and this predisposes some students to subject themselves to the sex-for-grades business. Finally, there is a general decline in morality and ethical values in the society that has contributed to sexual harassment being perceived, in some quotas, as near-normal. Moreover, the tertiary institutions are simple microcosms of the society.

Having examined the causes of the sex-for-grades activities, we then highlight some workable solutions to curb the menace and advance the quality of our educational system:

i. Whistleblowing policy: Different surveys across Nigerian tertiary institutions have clearly indicated that as high as $73 \%$ of sexual harassment cases might not be reported suggesting that the issue is extremely under reported. This is largely attributed to threat, fear of victimisation, shyness and lack of trust in the reporting and disciplinary systems. Thus, universities should set up strong whistleblowing policies that allow the reporting of sexual harassment while the identity of the reporter/victim is completely protected. Subsequently, discreet investigations by highly trusted academicians should be conducted to verify the claim and if found to be valid, the perpetrators should be punished according to the established regulations.

ii. Punishment: It is worthy of note that the Anti-Sexual Harassment in Tertiary Educational Institutions Bill recently passed second reading. However, so far, the major predicament is the successful implementation of punishment systems against the perpetrators within the universities. In fact, surveys have indicated that the lecturers engaged in sexual harassment are merely subjected to face disciplinary committees for formalities and even if found wanting, they are usually not punished. Therefore, we recommend the establishment of sound, functional and gender balanced disciplinary committees for sexual harassment which is open to receiving reports (through whistleblowing or other avenues). Also, the relevant university bodies responsible for implementing the recommendations of the disciplinary committee should be empowered to execute the duties diligently.

iii. Internal review systems (checks and balances): We propose that universities should initiate policies for courses to be taught and graded by more than one lecturer at every point in time. Furthermore, except for highly specialized courses with limited expertise, no lecturer should be allowed to instruct a course for more than three academic sessions. Also, internal vetting processes, within and across departments, should be initiated to confirm compliance during marking and results compilations.

iv. Sustained orientation and enlightenment campaigns: The university units in charge of sexual harassment policies should be empowered and mandated to use all available means to orient and 
enlighten both academics and students about the existence of the sexual harassment policies and what those policies entail. Perhaps, organising workshops and trainings may be worthwhile but the media drive should be the main focus.

v. Anti-"super-girl" awareness campaigns: Deliberate efforts should be made by institution towards re-orientating the female students to refrain from all sort of relationship with lecturers, except for academic purposes. This could be achieved by aggressive awareness campaigns via the social media platforms including short (dramatized) video clips that can easily go viral and subconsciously limit the feeling of a "supergirl" for relating with lecturers.

vi. Decent behaviour/dressing: Majority of female students across the Nigerian tertiary education system have revealed that indecent dressing is a major contributor to sexual harassment. Although, we are aware of the existence of dress codes in most of the institutions, we further suggest that deliberate efforts should be made to encourage students to respect such dress codes.

\section{vii. Academic Staff Union of Universities (ASUU) and other unions:}

There is no doubt that the ASUU and other university unions are important stakeholders in shaping the integrity of the Nigerian educational system. Therefore, the union should initiate activities aimed at enhancing professional ethics including sexual harassment policies, especially among the young academics. Furthermore, some sort of disciplinary measures from the union should be designed for misconducts and if it exists, there is a need to re-lunch such measures to enhance the professionalism and integrity of its members. At the least, the unions should distance themselves from perpetrators of sexual harassment, even by making statements. Furthermore, deliberate efforts by the unions should be made to debar any member with sexual abuse record/history from becoming an executive of the union at all stages.

\section{Acknowledgement}

This work was commissioned and supported by the Nigerian Young Academy.

\section{References}

Aceti, A., Gianserra, L., Lambiase, L., Pennica, A., and Teti, E. (2015). Pharmacogenetics as a tool to tailor antiretroviral therapy: a review, World Journal of Virology, 4(3); 198-208.

Ahmed I. and Tijjani H. (2019). A study of sexual harassment in six selected states owned colleges of north eastern states of Nigeria. International Journal of Innovative Research and Advanced Studies. 6(5): $100-108$.

Imonikhe J., Aluede O. and Idogho P. (2012). A survey of teachers' and students' perception of sexual harassment in tertiary institutions of Edo State, Nigeria. Asian Social Science. 8(1): 268-274.

Kullima, A. A., Kawuwa, M. B., Audu, B. M., Mairiga, A. G., and Bukar, M. (2010). Sexual assault against female Nigerian students. African Journal of Reproductive Health, 14(3): 189-193.

Nwadigwe, C. E. (2007). Unwilling brides: 'phallic attack'as a barrier to gender balance in higher education in Nigeria. Sex Education, 7(4): 351-369.

Ogbonnaya, L. U., Ogbonnaya, C. E., and Emma-Echiegu, N. B. (2011). Prevalence of sexual harassment/victimization of female students in Ebonyi State University Abakaliki, southeast Nigeria.Journal of Community Medicine and Primary Health Care, 23(1-2): 55-67.

Omonijo, D. O., Uche, O. C. O., Nwadialor, K. L. and Rotimi, O. A. (2013). A Study of Sexual Harassment in Three Selected Private Faith-Based Universities, Ogun-State, South-West Nigeria. Open Journal of Social Science Research, 1(9): 250-263.

Owoaje, E. T. and Olusola-Taiwo, O. (2010). Sexual Harassment experiences of female graduates of Nigerian tertiary Institutions. International Quarterly of Community Health Education, 30(4), 337-348. 